\title{
Moyamoya Hastalığı: Bir Olgu ile Gözden Geçirme
}

\section{Moyamoya Disease: Case Presentation and Review}

Haluk Gümüş ${ }^{1}$,

Halil Ekrem Akkurt ${ }^{2}$

Faruk Ömer Odabaş ${ }^{3}$,

Halim Yılmaz ${ }^{2}$,

Ramazan Şimşek ${ }^{4}$

${ }^{1}$ KTO Karatay Üniverstesi Medikana Tıp

Fakültesi Nöroloji Bölümü, Konya

${ }^{2}$ Sağlık Bilimleri Üniversitesi Konya Eğitim

ve Araştırma Hastanesi Fiziksel Tıp ve

Rehabilitasyon Bölümü, Konya

${ }^{3}$ Sağlık Bilimleri Üniversitesi Konya Eğitim ve

Araştırma Hastanesi Nöroloji Bölümü, Konya

${ }^{4}$ Toyotasa Acil Yardım ve Travmatoloji

Hastanesi, Sakarya

Geliş Tarihi/Received: 21 Aralık 2015

Kabul Tarihi/Accepted: 21 Mayıs 2018

\begin{abstract}
Öz
Moyamoya hastalığı ön ve orta serebral arterler ile internal karotid arterler arasındaki sahada obstrüksiyon veya stenoza bağlı olarak oluşan, etiyolojisi tam olarak bilinmeyen ve anjiyografik olarak tanımlanan bir durumdur. Erişkinlerde hemoraji, çocuklarda iskemi sıklıkla başlangıç semptomlarıdır. Bu yazımızda baş ağrısı, bulantı, kusma ve sol hemiparazi şikayetleri ile acil servisimize başvuran ve radyolojik bulguları sağ basal ganglion hemorajisini gösteren 21 yaşında erkek hastada teşhis edilen bir Moyamoya Hastalığı vakası sunuyoruz
\end{abstract}

Anahtar Kelimeler: Moyamoya, hemoraji, erken inme, yetişkin, anjiografi

Abstract

Moyamoya disease is an entity, which is caused by obstruction or stenosis in the area between the internal carotid artery, and anterior and middle cerebral arteries, identified angiographically, and does not have an exactly known etiology. The most frequent symptoms of onset are hemorrhage in adults and ischemia in children. In this paper, we present a case of Moyamoya disease which was diagnosed with a 21 year old male patient who was admitted to our emergency department with headache, nausea vomiting and left hemiparasi complaints and whose radiological findings showed right basal ganglia hemorrhage.

Keywords: Moyamoya, hemorrhage, hemiparasi, adult, angiography

\section{GíRiş}

Moyamoya hastalığı; supraklinoid internal karotis arter ve Willis poligonundaki ana dallarının genellikle bilateral, idiopatik progresif ilerleyici oklüzyonu ya da stenozu ile karakterize primer vasküler bir hastalıktır. Gelişen oklüzyona kompansatuvar olarak oklüzyonun distalinden başlayarak yavaşça ilerleyen yaygın vasküler kollateraller gelişir. Oluşan bu anormal revaskülarizayon anjiografide sigara dumanına benzer bir görüntü vermektedir. Hastalıkta ismini Japonca'da 'sigara dumanı' anlamına gelen 'moyamoya' dan almaktadır (1). Etiyolojide herediter faktörler yer almakla birlikte, çoğu olgu sporadiktir (2). İlk semptomlar rekürren baş ağrısından, akut hemiplejiye ve epilepsiye kadar değişen bir çeşitlilikte kendini gösterir. Klinik tablo ve başvuru, çocuklarda ve erişkinlerde farklılıklar göstermektedir. Çocuklarda iskemik semptomlar ön planda iken, erişkinlerde kanamaya ait semptomlar ön plandadır. Kanama insidansının erişkinde $\% 60$, çocuklarda ise \%10 olduğu bildirilmiştir. Erişkinlerde ise hastalık kendisini genellikle kanama ile göstermektedir. Kanama subaraknoid, intraventriküler, subdural veya intraserebral olabilir Willis poligonunda bilhassa posterior sirkülasyondaki küçük anevrizmalar ve anormal dilate moyamoya damarlannda gelişen mikroanevrizmalar kanamaya yol açar (3). Çocuklarda iskemik bulgular hiperventilasyon veya yüksek ateşle agreve olur (4). Kesin tanı anjiografi ile konur (5). Bu olgu sunumu ülkemizde nadir görülen bir hastalık olan moyamoya hastalığının farklı klinik tablolar ile acil servise gelebileceği, genç inmenin sebeplerinden biri olabileceği ve tanısının akla geldiği zaman kolayca konup erken tedavi edilebileceğini hatırlatmak için yazılmıştır.

\section{OLGU SUNUMU}

Yaklaşık 7-8 yıldır gerilim tipi baş ağrısı ile birçok kez poliklinik başvuruları olan 38 yaşında erkek hastanın 1 yıl önce polikliniğimize başvurusunda yine sık sık olan şiddetlenmeyen ancak rahatsız edici baş ağrısı olması nedeni ile kranial MRG (Manyetik rezonans görüntüleme) çekilmiş ve yaşı ile uyumlu olmayacak şekilde yaygın iskemik alanlar görülmüş (Şekil 1-2).

Bunun üzerine hastaya ileri radyolojik ve biyokimyasal tetkikler planlanmış. Biyokimyasal ve hematolojik bakısında hemogram, rutin biyokimya, tiroid fonksiyon testleri, Prot $\mathrm{C}$, Prot $\mathrm{S}$, antitrombin 3, faktör 5 leiden mutasyonu, protombin 2 gen mutasyonu, antinükleer antikor, kompleman düzeyleri ve diğer vaskülit markerleri negatif olarak gelmiş.

Hastaya yapılan anjiografi sonucunda her iki internal ve eksternal karotid arter uç dallarda darlık ve

Yazışma Adresi: Halil Ekrem Akkurt, Konya Eğitim ve Araştırma Hastanesi Fiziksel Tıp ve Rehabilitasyon Bölümü, Konya.

e-posta: ekremakkurt@yahoo.com

Atıf yapmak için: Gümüş H, Akkurt HE, Odabaş FÖ, Yılmaz RŞ. Moyamoya Hastalığı: Bir Olgu ile Gözden Geçirme. Selcuk Med J 2018;34(3): 125-128 


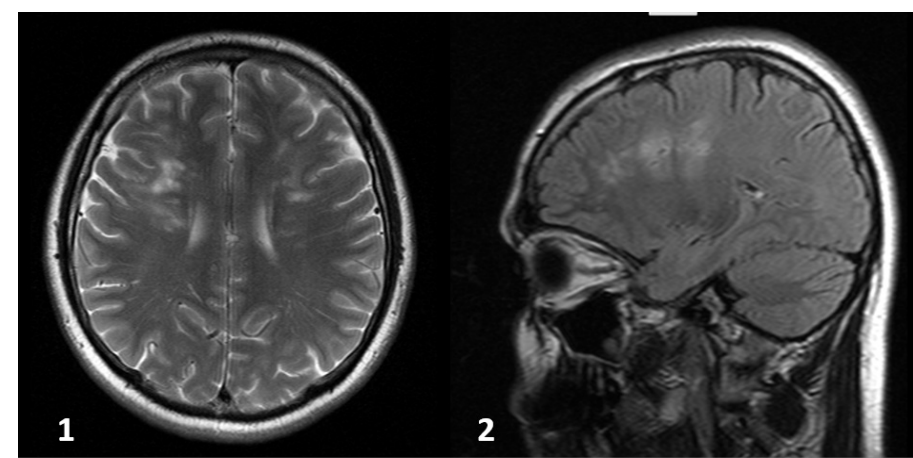

Şekil 1-2. T2 Axial-Sagittal kesitte yaygın iskemik alanlar

anevrizmatik genişlemeler (Şekil 3-4) olması nedeni ile Moya Moya hastalığı teşhisi konmuş ve düşük doz asetil salisilik asit tedavisi başlanmış, cerrahi tedavi düşünülmemiş.

Hasta bu tedavi ile düzenli poliklinik kontrollerine gelmekte iken ani gelişen sol kol ve bacakta güçsüzlük, baş ağrısı ve bulantı kusma şikayetleri ile acil servise başvurdu. Yapılan beyin BT incelemesinde sağ basal ganglion seviyesinde sağ lateral ventriküle açılan kanama (Şekil 5) tespit edilmesi üzerine servise yatırıldı. Antiödem ve semptomatik tedavi uygulandı. Beyin BT kontrolleri ile kanama çapı takip edildi.

Takibinin ikinci ayında kontrol BT de kanamanın kaybolması ve yapılan rehabilitasyon programı sonrası kliniğinin tamamen düzelmesi üzerine olgu beyin cerrahisi kliniğine cerrahi tedavi planlanması amacıyla sevk edildi ancak hasta cerrahi tedaviyi kabul etmedi ve düşük doz antiagregan tedavi ile takip edilmesine karar verildi.

\section{TARTIŞMA}

Moyamoya hastalığı; nedeni tam olarak bilinmeyen,

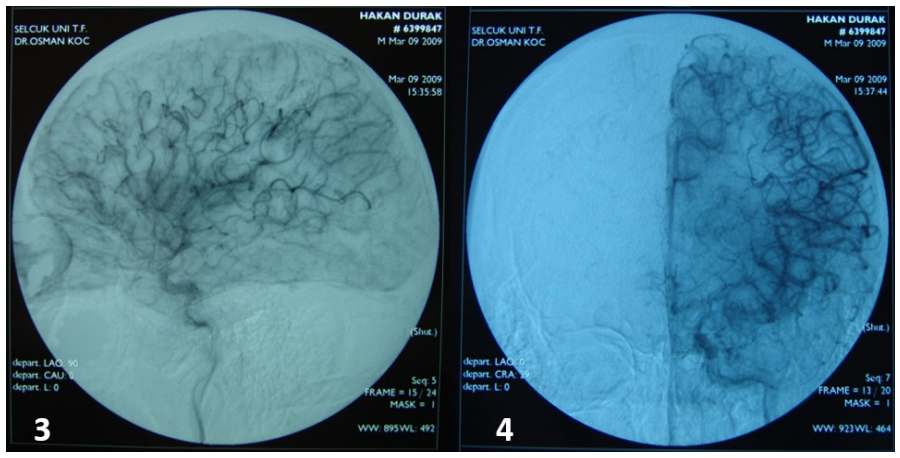

Şekil 3-4. Saggital-Aksiyal anjio grafide yaygın damarlarda iskemik daralmalar

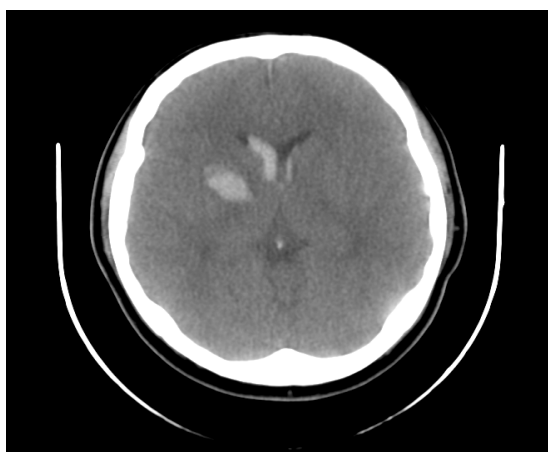

Şekil 5. BT de sağ putamen seviyesinde ventrikül içine açılan kanama

histopatolojik olarak suprasellar intrakraniyal internal karotid arter stenozu ile sonuçlanan, fibroselüler intimal kalınlaşma, düz kas proliferasyonu, artmış elastin birikimi ile oluşan bir hastalıktır (1). Wills poligonu çevresinde çok sayıda perforan anastomozlar görülür (2).

Moyamoya hastalarının \%90'ı japondur. Japonya'daki yıllık prevalansı ise 3.16 / 100,000 olup, Japonya'nın en sık pediatrik serebrovasküler hastalığıdır. Avrupaki yılık insidans ise Japonya'nın 1/10'u kadardır. Moyamoya hastalığının 1-5 yaşlarında ve 36-40 yaşları arasında olmak üzere 2 pik yaptığı ve tanı konulan olguların yaklaşık yarısının 10 yaş altında olduğu dikkat çekmektedir $(6,7)$. Histopatolojik çalışmalarda asıl lezyonun fibrosellüler intimal kalınlaşma ve elastik laminada tabaka artışı olduğu gözlenmiştir. Kalınlaşmış intimada elastin birikimi dikkati çekmiş ve bu hücrelerde elastin mRNA'sının artığı gösterilmiştir (8). Otopsi çalışmalarında ayrıca subaraknoid mesafe içerisinde dilate, ince duvarlı, adale tabakası olmayan kollateral damarların varlığına dikkat çekilmiştir. Patolojik incelemelerde çocuk ve erişkin yaş gruplarındaki bulgular arasında anlamlı bir farklılık saptanmamıştır (1). İlgili genetik loküslerin 3, 6, 8 ve 17. kromozomlarda (3p [MYMY1], 17q25 [MYMY2; 607151], 8q23 [MYMY3; 608796], 6. kromozom, D6S441) olduğu yolunda çalışmalar mevcuttur. Genetik bağlantının Japon ırkında anlamlı şekilde daha yüksek olduğu dikkat çekmekle beraber, hastalığa siyah ırk da dahil olmak üzere dünyanın her yerinde rastlanılmaktadır (9). Moyamoya hastalarında HLA antijenleri incelenmiş ve DQB1*0502 geninin hastalık ile ilişkili olabileceği düşünülmüştür (10). İnsan lökosit antijeni B51'in, moyamoya olgularında anlamlı olarak yüksek tespit edilmesi de dikkat çekicidir (4). Yine hastalığın patogenezinde fibroblast 
büyüme faktörü, prostoglandin E2 gibi mediatörler ile Epstein-Barr virüsü gibi enfeksiyöz ajanların rol oynadığı düşünülse de hastalığın patogenezi net olarak aydınlatılamamıştır (11). Vasküler tıkanıklık ve darlıklar sonucunda beynin iskemik dokularını besleyebilmek amacı ile kollateraller gelişir. Bazal gangliyonlar seviyesinde gelişen kollateraller, leptomeningiyal ve transdural kollateraller ile PCA'dan kollateraller iskemik parankimin beslenmesini sağlar (12). Hastalığa bağlı morbidite kan akımındaki azalma ile direkt olarak ilişkilidir. Kan akımındaki azalma özellikle frontal lobda izlenirken temporal ve oksipital bölgelerde akım nispeten normal seviyelerde kalmaktadır (13).

Moyamoya hastalığı bimodal dağılım gösterir. Çoçuklarda ortalama 2-17 yaşlar arasında görülürken; erişkinlerde 30-40 yaşlar arasında görülür. Kliniğe iskemik olaylar, baş ağrısı, nöbetler, hareket bozukluğu (kore, distoni, hemikore, atetoz), mental kötüleşme, intrakraniyal hemoraji, geçici iskemik ataklar ile yansır $(14,15)$. Hastamızında ilk polikliniğimize başvuru sebebi baş ağrısı şeklinde olup acil servise ise motor defisit ve baş ağrısı, bulantı-kusma şikayetleri ile başvurmuştur.

Moyamoya hastalığında altın standart ve tanı koydurucu yöntem anjiyografidir. Anjiyografide; distal internal karotid arterlerin stenozu veya tam tıkanması, anterior ve orta serebral arterlerin proksimal kısımlarının silik görülmesi, beynin bazal kısımlarında iyi gelişmiş moyamoya damarlarının görülmesi, kortikal arterlerin kendi aralarında veya kortikal arterlerle leptomeningeal arterler arasındaki kollaterallerin görülmesi gibi bulgular saptanabilir (5) Bizim olgumuzda literatüre benzer şekilde konvansiyonel anjiografi ile kesin tanısı konmuştur.

Tanıda ayrıca Beyin tomografisinde (BT) multipl infarkt, beyin atrofîsi, subaraknoid boşluklarda genişleme ve ventriküler dilatasyon görülebilmektedir. Kontrastlı BT'de ise bazal serebral damarların az kontrast tutması önemli bir belirti olabilir. Kontrastlı kesitlerde giral tutulum izlenirse ameliyat için opaklaşmanın kaybolması beklenmesi önerilmektedir(16). Manyetik rezonans (MR) görüntüleme tekniğinin kullanıma girmesi ile moyamoya hastalığında MR bulguları sıkça rapor edilmeye başlanmıştır. Bu bulgulardan en önemli iki tanesi: 1. Orta serebral arterin terminal kısmında "flow-void" görüntünün görülmemesi veya azalması, 2. Bazal ganglionda perforan damarlara bağlı "flow-void" görüntünün ortaya çıkmasıdır (17). MR görüntüleme tekniğinin moyamoya tanısındaki radyolojik spesifikliği \%100, sensitivitesi ise \%73'tür. MR görüntüleme tekniğinin sensitivitesi 1.5 Tesla'lık incelemelerde MR + MR-anjiyografi (MRA) şeklinde çalışıldığında \%92'ye çıkmaktadır (18).

Moyamoya hastalığının tedavisinde amaç iskemik belirtileri önlemek ve kanama olasılığını en aza indirmektir. Ancak hastalığın etyopatogenezinin net olarak ortaya konabilmesi ne kadar mümkün olamadı ise patolojik progresyonu durduracak ya da tersine çevirecek tam bir tedavi modalitesi de henüz mevcut değildir. Tedavi edilmeyen moyamoya olgularında morbidite \%70' ten fazladır. Moyamoya hastalığında medikal tedavinin yeri ancak semptomatik veya palyatif düzeydedir. Bu olgular için progresyonu durduracak veya tersine çevirebilecek bir medikal tedavi yoktur. İki tip ilaç grubu ile ancak destek tedavi verilmesi söz konusudur. Bunlardan ilki antikoagülan/ antitrombotik tedavidir. Bu amaçla aspirin (6 yaş altı $81 \mathrm{mg} / \mathrm{gün}$, adolesanlarda ve erişkinde $325 \mathrm{mg} /$ gün) veya düşük moleküler ağırlıklı heparin $(0,5 \mathrm{mg} /$ kg günde 2 kez subkutan) kullanılmaktadır. İkinci grup medikal tedavide ise kalsiyum kanal blokerleri kullanılmaktadır. Kalsiyum kanal blokerlerinin, moyamoya olgularında karşılaşılan dirençli başağrısı ve migrende etkili olabildiği gösterilmiştir. Ayrıca kalsiyum kanal blokerlerinin dirençli geçici iskemik ataklarda atakların sıklık ve şiddetini azaltmada etkili olduğu da rapor edilmiştir $(4,19)$.

Günümüzde moyamoya olgularında serebral kan akımını arttırmaya yönelik cerrahi girişim yöntemleri genel kabul gören tedavi şeklidir. Bu tip cerrahi girişimlerden yarar görebilecek ideal hastalar rekürren progresif iskemik olayları olan olgular ve azalmış serebral perfüzyon rezervi olan olgulardır. Uygulanan cerrahi revaskülarizasyon yöntemleri; direkt teknikler, indirekt teknikler ve kombine teknikler olarak üç ana grupta incelenebilir. Direkt tekniklerde en önemli kural, moyamoya hastalığının düşük serebral kan akımının (20-25 ml/100 g/dk) söz konusu olduğu bir patoloji olduğunu göz önünde bulundurup, revaskülarizasyon için kullanılacak greftin de düşük akımlı greft olması gerekliliğini akılda tutmaktır. Bu amaçla süperfisyal temporal arter (STA)- orta serebral arter (OSA), STA-distal anterior serebral arter (ASA), oksipital arter (OA)-OSA ve OAposterior serebral arter (PSA) anastomozları yapılabilmektedir(20). İndirekt tekniklerde prensip, pedinküllü donör doku kullanılarak beyin yüzeyi ile donör arasında spontan anjiogenezin indüklenmesidir. Bu amaçla STA, dura, temporal adele ve galea kullanılmaktadır. Kullanılan yöntemler arasında; encephaloduro-arterio-synangiosis (EDAS), 
encephalo-myo-synangiosis (EMS), encephaloduro-arterio-myo-synangiosis (EDAMS), encephalomyo-arterio-synangiosis (EMAS), encephalogaleo-periosteal-synangiosis (EGPS), split duroencephalosynangiosis ve çoklu kraniyal uygulamalar sayılabilir (21). Hemorajik tip Moyamoya hastalığında yeniden kanamadan korunmayı sağlayacak daha üst bir tedavi gösterilememiştir $(22,23)$

Biz olgumuza polikliniğimize başvurduğu sırada literatüre uygun şekilde tedavisini planladık ve Asetil salisilik asit başladık. Ancak takipler sorunsuz gitmekte iken spontan intraserebral hemoraji gelişmesi tedaviyi güçleştirmiştir. Hastanın cerrahi revaskülarizasyon tedavisini kabul etmemesi üzerine antiagregan tedaviye ve ev egzesiz programına devam etmesini önererek rutin takiplerine devam etmesini önerdik.

\section{SONUÇ}

Biz bu olgu sunumunda ülkemizde nadir görülmesine rağmen dirençli baş ağrılarında ve erken yaşta inme geçiren hastaları araştırırken bu hastalığın akılda bulundurulması ve antiagregan tedavi başladıktan sonra mutlaka hastanın sık kontrollere gelmesi konusunda uyarılmasını hatırlatmak istedik.

Çıkar Çatışması: Çalışmada herhangi bir çıkar çatışması yoktur.

Finansal Çıkar Çatışması: Çalışmada herhangi bir finansal çıkar çatışması yoktur.

Yazışma Adresi: Halil Ekrem Akkurt, Konya Eğitim ve Araştırma Hastanesi Fiziksel Tıp ve Rehabilitasyon Bölümü, Konya.

E-posta: ekremakkurt@yahoo.com

\section{KAYNAKLAR}

1. Yamamoto M, Aoyagi M, Tijima S. Increase in elastin gene expresion and protein synthesis in arterial smooth muscle cell derived from patients with moyamoya disease. Stroke 1998;28:1733-8.

2. Suzuki J, Kodowa N. Moyamoya disease. Stroke 1983;14: 104-9.

3. Houkin K, Kamiyama $\mathrm{H}$, Abe $\mathrm{H}$, et al. Surgical therapy for adult moyamoya disease. Stroke 1996;27:1342-6.

4. Matsushima Y. Moyamoya Disease. Principles and practice of pediatric nerosurgery. New York: Thieme, 1999:1053-70.

5. Kinugasa K, Mandai S, Kamata I, et al. Surgical treatment of moyamoya disease: Operative technique for encephaloduroarterio-myo-synangiosis, it's follow-up, clinical results and angiograms. Neurosurgery 1993;32:527-31.

6. Burke GM, Burke AM, Sherma AK, et al. Moyamoya disease: A summary. Neurosurg Focus 2009;26 (4):11.

7. Kuroda S, Houkin K. Moyamoya disease: Current concepts and future perspectives. Lancet Neurol 2008:1056-66.

8. Schmit BP, Burrows PE, Kuban K, et al. Acquired cerebral arteriovenous malformation in a child with moyamoya disease. J Neurosurg 1996;84:677-80.
9. Yamauchi T, Tada M, Houikin $\mathrm{K}$, et al. Linkage of familial moyamoya disease (Spontaneous occlusion of the circle of Willis) to chromosome 17q2. Stroke 2000;31(4): 930-5.

10. Ikeda $H$, Sasaki $T$, Yoshimoto $T$, et al. Mapping of a familial moyamoya disease gene to chromosome 3p24.2-p26. Am J Hum Genet 1999;64:533-7.

11. Malek AM, Connors S, Robertson RL. Elevation of cerebro spinal fluid levels of basic fibroblast growth factor in Moyamoya and central system disorders. Pediatr Neurosurg 1997;27:182-9.

12. Fukui M. Guidelines for the diagnosis and treatment of spontaneous occlusion of thecircle of Willis ('Moyamoya' disease). Research Committee on Spontaneous Occlusion of the Circle of Willis (Moyamoya Disease) of the Ministry of Health and Welfare, Japan. Clin Neurol Neurosurg 1997;99:238-40.

13. Jayakumar PN, Vasudev MK, Srikanth SG. Posterior circulation abnormalities in moyamoya disease: A radiological study. Neurology India 1999;47:112-7.

14. Menkes JH.Cerebrovascular disorders.In: Menkes JH, ed. Textbook of child neurology. 5th ed. Baltimore: Williams and Willkins, 1995:702-24.

15. Masuda J, Ogata J, Yamaguchi T. Moyamoya disease. In: Barnett HJM, Mohr JP, Stein BM, Yatsu FM, eds. Stroke: Pathophysiology, diagnosis, and management. 3th ed. New York: Churchill Livingstone, 1998:815.

16. Ohta T, Tanaka H, Kuroiwa T. Diffuse leptomeningeal enhancement, "ivy sign" in magnetic resonance images of moyamoya disease in childhood: Case report. Neurosurgery 1995;37:1009-12.

17. Pereira PL, Farnsworth CT, Duda SH, et al. Pediatric moyamoya syndrome. AJR 1996;167: 526-8.

18. Suzuki $Y$, Negoro $M$, Shibuya $M$, et al. Surgical treatment for pediatric moyamoya disease: Use of the superficial temporal artery for both areas supplied by the anterior and middle cerebral arteries. Neurosurgery 1997;40:324-30.

19. Smith JL. Understanding and treating moyamoya disease in children. Neurosurg Focus 2009;26 (4):4.

20. Reis CVC, Safavi-Abbasi S, Zabramski JM, et al. The history of neurosurgical procedures for moyamoya disease. Neurosurg Focus 2006;20(6):7.

21. Veeravagu A, Guzman R, Patil CG, et al. Moyamoya disease in pediatric patients: Outcomes of neurosurgical interventions. Neurosurg Focus 2008;24(2):16.

22. Kamiyama $\mathrm{H}$, Takahashi $\mathrm{A}$, Houkin $\mathrm{K}$, et al. Visualization of the ostium of an arteriotomy in bypass surgery. Neurosurgery 1993;33:1109-10.

23. Ishikawa $\mathrm{T}$, Houkin $\mathrm{K}$, Kamiyama $\mathrm{H}$, et al. Effects of surgical revascularization on outcome of patients with pediatric Moyamoya disease. Stroke 1997;28:1170-3. 